\title{
Endocrine markers of puberty timing and antisocial behaviour in girls and boys
}

\author{
Philip Jules Simon Michielsen ${ }^{1,2}$ (1) | Sabine Judith Roza ${ }^{1,3}$ | \\ Hjalmar Johan Carel van Marle ${ }^{4}$
}

\footnotetext{
${ }^{1}$ Department of Psychiatry, Erasmus Medical Center, Rotterdam, the Netherlands

${ }^{2}$ Mental Health Institute, GGZ Westelijk

Noord-Brabant, Halsteren, the Netherlands

${ }^{3}$ Department of Science and Education, Netherlands Institute for Forensic Psychiatry \& Psychology, Utrecht, the Netherlands

${ }^{4}$ Department of Forensic Psychiatry, Erasmus Medical Center, Erasmus School of Law,

Rotterdam, the Netherlands

\section{Correspondence}

Philip Jules Simon Michielsen, Department of Psychiatry, Erasmus Medical Center,

Rotterdam, the Netherlands.

Email: p.michielsen@ggzwnb.nl
}

\begin{abstract}
Background: Early puberty is associated with higher than average risk of antisocial behaviour, both in girls and boys. Most studies of such association, however, have focused on psychosocial mediating and moderating factors. Few refer to coterminous hormonal measures.
\end{abstract}

Aim: The aim of this review is to consider the role of hormonal markers as potential mediating or moderating factors between puberty timing and antisocial behaviour.

Method: A systematic literature search was conducted searching Medline, Embase, Web of Science, Scopus, Psycinfo, Cochrane and Google Scholar.

Results: Just eight studies were found to fit criteria, all cross-sectional. Measurements were too heterogeneous to allow meta-analysis. The most consistent associations found were between adrenal hormones-both androgens and cortisol-which were associated with early adrenarche and antisocial behaviours in girls and later adrenarche and antisocial behaviour in boys.

Conclusions: The findings from our review suggest that longitudinal studies to test bidirectional hormone-behaviour associations with early or late puberty would be worthwhile. In view of the interactive processes between hypothalamic-pituitary-adrenal and hypothalamic-pituitary-gonadal axes, integrated consideration of the hormonal end products is recommended. 


\section{1 | INTRODUCTION}

Antisocial behaviour in children and adolescents is defined as behaviour by which basic norms, rights and rules are violated. Antisocial behaviour includes various inappropriate behaviours such as oppositional and aggressive behaviour, disruptive behaviour disorders and delinquency. Such behaviour disorders in children increase risk of several negative outcomes in adulthood including criminal offending, unemployment and psychiatric disorders such as mood disorders, anxiety disorders and substance abuse (Farrington, 1995; Maughan \& Rutter, 2001). Disruptive behaviour disorders (DBDs), covering both oppositional defiant disorder (ODD) and conduct disorder (CD) can start in early childhood or adolescence, and often continue into adulthood, putting a heavy burden on individuals, families, justice and health care systems (Moffitt, 2006; Odgers et al., 2008). During puberty, numerous alterations occur in the brain and the body, including hormonal changes, physical development and reorganisation of different brain structures. Whereas puberty typically refers to the activation of the hypothalamic-pituitary-adrenal axis (HPA-axis) eventually resulting in gonadal maturation (Sisk \& Foster, 2004), adolescence is rather conceived as the developmental stage between childhood and adulthood, largely covering the second decade of life, in which social and cognitive behaviours mature.

Two components of puberty, adrenarche and gonadarche, are important in the study of puberty timing (Grumbach \& Styne, 2003). Adrenarche typically starts between ages 6 and 9 years and refers to the maturation of the HPA-axis. In this period, adrenal androgens like dehydroepiandrosterone (DHEA) and its sulphate (DHEA-S) begin to rise. The diagnosis of premature adrenarche (PA) is acceptable when clinical signs of androgen action, such as adult type body odour, appear before the age of 8 years in girls or 9 years in boys and are associated with adrenal androgen concentrations which are high for the chronological age (Voutilainen \& Jääskeläinen, 2015). Gonadarche, generally starting between 9 and 11 years, refers to the maturation of the hypothalamic-pituitary-gonadal (HPG) axis. The hypothalamus stimulates hormones including gonadotropins (follicle stimulating hormone $[\mathrm{FSH}]$ and luteinising hormone [LH]), which in turn stimulate sex steroids, such as testosterone, oestradiol and progesterone, which influence gonadotropin production, and so on in a feedback loop. These hormones rise rapidly during the pubertal transition (Nottelmann et al., 1987). Early maturity may bring imbalance in behavioural adaptation since the brain's sensitivity to HPA/HPG axis hormones may be higher than among young people who mature at the usual time. Both during and after completion of puberty early maturers may secrete higher doses of these hormones (Mendle, Turkheimer, \& Emery, 2007).

As well as timing of puberty onset, pubertal stage and tempo must be considered. Pubertal stage, generally rated according to the Tanner Scale, refers to the development of external, physical primary and secondary sexual characteristics and is highly correlated with age, whereas puberty timing refers to the degree of pubertal maturation relative to that of same-sex and same-age peers and is often referred to as early, on-time or late pubertal timing. Tempo describes the rate at which individuals progress from Tanner Stage I to Stage V (full sexual maturity). Most research has emphasised puberty timing as particularly relevant for understanding adolescence onset of DBDs. Higher pubertal stage in itself is likely to be related to aggressive and rule breaking behaviours (Hemphill et al., 2010; Oldehinkel, Verhulst, \& Ormel, 2011), while fast tempo has been associated with externalising behaviours in both boys and girls (Beltz, Corley, Bricker, Wadsworth, \& Berenbaum, 2014; Marceau, Ram, Houts, Grimm, \& Susman, 2011). Kretschmer, Oliver, and Maughan (2014) showed that both earlier timing and faster tempo predicted delinquency in both girls and boys.

The position is less clear with respect to any relationships between the hormonal end-products of HPA (cortisol and DHEA(-S)) and HPG axes (testosterone and oestradiol) and adolescent DBDs or antisocial behaviour. Alink et al. (2008), in a meta-analysis, found that externalising behaviours were not significantly associated with cortisol levels in adolescents, while in elementary school-aged children there was an association with lower basal cortisol (hypoactivity). A separate analysis for cortisol reactivity showed no association. In some individual studies, rapid increase in DHEA and DHEA-S during adrenarche has been positively related to CD and ODD in boys (Mundy et al., 2015; Van Goozen, Matthys, Cohen-Kettenis, \& Buitelaar, 2000; Van Goozen, Matthys, Cohen-Kettenis, Thijssen, \& Van Engeland, 1998) and girls (Belsky, Ruttle, Boyce, Armstrong, \& Essex, 2015). In others, negative associations were found among boys (Nottelmann et al., 1987; Susman et al., 1987) or no association (Shirtcliff, Zahn-Waxler, 
Klimes-Dougan, \& Slattery, 2007). Among girls, two studies found a negative association (Nottelmann et al., 1987; Susman, Granger, Murowchick, Ponirakis, \& Worral, 1996).

Testosterone levels rise up to 30 -fold during puberty in boys. In adolescents testosterone levels and aggressive behaviour have been associated in childhood-onset persistent antisocial behaviour (Maras et al., 2003), clinicreferred adolescents (Scerbo \& Kolko, 1994) and male offenders (e.g. Dabbs, Jurkovic, \& Frady, 1991). In some community-based studies these associations have not been replicated from age 16 on (Tremblay et al., 1997; Van Bokhoven et al., 2006). For oestradiol, a review on the relationship of oestradiol with aggression, $C D$ and delinquency yielded no significant correlations (Balzer, Duke, Hawke, \& Steinbeck, 2015).

Most studies on the association of puberty timing and DBDs have focused on psychosocial mediating and moderating factors, such as ethnicity, peer and other environmental influences (Celio, Karnik, \& Steiner, 2006; Graber, 2013; Mendle et al., 2007; Negriff \& Susman, 2011). Previous reviews have focused either on the relationship between puberty timing or tempo and antisocial behaviour or on hormonal (adrenal or gonadal) associations with antisocial behaviour and DBDs, but not taken both together. Furthermore, in the light of the possibility that different results found for hormonal assessments in antisocial behaviour during adolescence and because puberty timing may influence antisocial behaviour differently depending on sex (see, Ullsperger \& Nikolas, 2017), we were interested in sex differences with respect to these hormones. Our aim was to review the evidence for the following research questions:

1. Which associations have been found for adrenal and/or gonadal hormones in studies focusing on the relationship between puberty timing and antisocial behaviour?

2. Are the associations with these adrenal or gonadal hormones different for girls and boys?

\section{2 | METHOD}

A systematic literature search for publications on puberty timing/tempo, adrenal and gonadal hormones and antisocial behaviour, with narrative analysis, was undertaken using an adaptation of the Sample, Phenomenon of Interest, Design, Evaluation, Research (SPIDER) model (Cooke, Smith, \& Booth, 2012). Relevant studies on puberty timing and antisocial behaviour were identified by using Medline (Ovid SP), Embase, Web of Science, Scopus, Psycinfo, Cochrane and Google Scholar. Search terms included ("puberty," "menarche," "adrenarche") AND ("antisocial behaviour," "criminal behaviour," "delinquency," "violence," "aggression," "conduct disorder," "externalising"). For the full list and search strategies adjusted for each database, see Appendix S1. The SPIDER model structured the search terms and eligibility of the criteria (see Table 1). The search covered the period January 1, 1985 to March 28, 2018, as the research on biological correlates of antisocial behaviour started in the mid-1980s. Exclusion and inclusion criteria for paper selection are listed in Table 1. In brief we included papers about children/adolescents aged 5-18, which measured relevant hormones and puberty timing or tempo but not staging and scaled measures of antisocial or disruptive behaviours. We excluded studies on known genetic or organic causes of precocious puberty, as these are rare and are often complicated by somatic comorbidity for which treatment like, for example, brain surgery or administration of gonadotropin releasing hormone agonists is needed.

Title and abstract were screened by two independent researchers. An overall agreement level of $95 \%$ was achieved. In a final meeting the remaining $5 \%$ were discussed and $100 \%$ consensus was achieved.

\section{$3 \quad$ RESULTS}

The searches yielded 2,811 unique titles (see Figure 1). In total, 124 articles were selected for full text reading. Within these results we excluded existing reviews on the association of puberty timing or tempo and antisocial behaviour and included studies in which HPA/HPG axis hormones were studied as potential mediators or 
TABLE 1 SPIDER inclusion-exclusion criteria

\begin{tabular}{|c|c|c|}
\hline & Inclusion & Exclusion \\
\hline Sample & $\begin{array}{l}\text { Children-adolescents }>5 \text { years with externalising } \\
\text { disorders }\end{array}$ & $\begin{array}{l}\text { Substance use disorders or ADHD } \\
\text { without antisocial behaviour } \\
\text { Children: } 0-5 \text { years } \\
\text { Adults: }>18 \text { years }\end{array}$ \\
\hline $\begin{array}{c}\text { Phenomenon } \\
\text { of interest }\end{array}$ & $\begin{array}{l}\text { Studies on puberty timing in boys/girls/mixed gender } \\
\text { combined with hormonal measure (HPA and/or HPG } \\
\text { axis) }\end{array}$ & $\begin{array}{l}\text { Puberty staging or pubertal tempo } \\
\text { Studies on puberty timing without } \\
\text { hormonal measures or other hormona } \\
\text { measures } \\
\text { Central or peripheral precocious puberty } \\
\text { with known genetic or organic cause }\end{array}$ \\
\hline Design & $\begin{array}{l}\text { Peer-reviewed journals with all empirical approaches } \\
\text { (observational, retrospective, prospective, } \\
\text { cross-sectional, cohort studies) }\end{array}$ & $\begin{array}{l}\text { Non-peer reviewed journal, book } \\
\text { chapter, conference proceedings, PhD } \\
\text { thesis } \\
\text { Review articles, meta-analysis, opinion, } \\
\text { new direction }\end{array}$ \\
\hline Evaluation & $\begin{array}{l}\text { Hormonal (HPA and/or HPG axis) measures associated } \\
\text { with puberty timing or tempo }\end{array}$ & $\begin{array}{l}\text { Other hormonal measures or } \\
\text { neuropeptides, for example, } \\
\text { vasopressin or oxytocin }\end{array}$ \\
\hline $\begin{array}{l}\text { Research } \\
\text { type }\end{array}$ & $\begin{array}{l}\text { Peer-reviewed journal articles published between } 1985 \\
\text { and March } 2018 \text { with full text available in English }\end{array}$ & $\begin{array}{l}\text { Peer-reviewed journals published before } \\
\text { January } 1985 \text { or after March } 2018 \\
\text { Full text in other language than English }\end{array}$ \\
\hline
\end{tabular}

Abbreviation: ADHD, attention deficit hyperactivity disorder; HPA, hypothalamic-pituitary-adrenal; HPG, hypothalamicpituitary-gonadal; SPIDER, "Sample, Phenomenon of Interest, Design, Evaluation, Research" Model.

independent variables, although checked their reference lists, leaving eight studies for inclusion which incorporated hormone assessments in the association between puberty timing and onset of antisocial behaviour (see Table 2).

In all included studies antisocial behaviour of some kind had to be treated as the dependent variable and puberty timing as an independent variable. Puberty timing was measured in different ways between studies. The most common methods were variants of Tanner staging (genital and pubic hair stage for boys; breast and pubic hair stage for girls) by physical examination, or by children's or adolescents' reports and/or parent report by confirming stage according to standard Tanner pictures, or by the Pubertal Development Scale (Petersen, Crockett, Richards, \& Boxer, 1988), a five-item self-report questionnaire that assesses body hair, growth speed and secondary sex changes in both girls and boys. In studies of girls only, self-reported age of menarche was accepted as evidence of timing. These methods are not interchangeable in terms of validity. Clinician-reported Tanner stages are more accurate than other methods, while selfreported age of menarche has been shown less valid in longitudinal studies (Dorn, Dahl, Woodward, \& Biro, 2006). Early puberty timing, based on cut-off scores for Tanner staging, was compared to on-time or late onset adolescents within most studies; in two studies (Graber, Brooks-Gunn, \& Warren, 2006; Sontag, Graber, Brooks-Gunn, \& Warren, 2008) the sample was stratified according to national norm groups adjusted for age, gender and ethnicity.

We grouped studies that specifically dealt with timing of adrenarche and gonadarche separately because these are independent events controlled by separate mechanisms (Ibanez, Dimartino-Nardi, Potau, \& Saenger, 2000).

\subsection{Timing of adrenarche and behavioural difficulties among girls}

Girls with DHEA(S) PA, meaning high levels of DHEA and Tanner Stage 2 pubic hairs in 6-8-year-olds, had higher adrenal androgen concentrations than on-time adrenarche girls and they more often met criteria for ODD and DBD according to 
Puberty AND antisocial outcomes (7 databases):

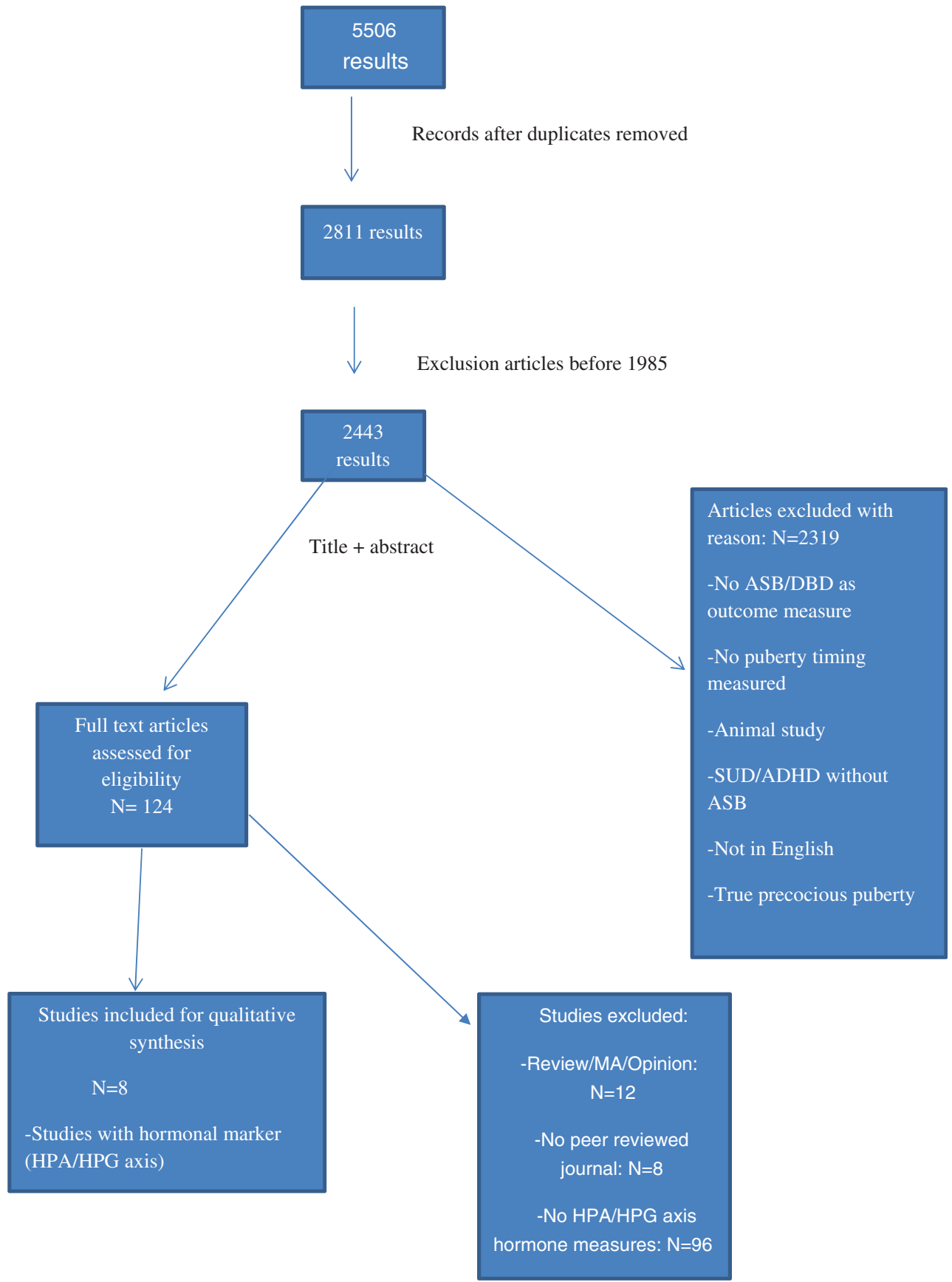

FIGURE 1 PRISMA flow diagram search. ADHD, attention deficit hyperactivity disorder; ASB, antisocial behaviour; DBD, disruptive behaviour disorders; HPA, hypothalamic-pituitary-adrenal; HPG, hypothalamic-pituitarygonadal; MA, meta-analysis; SUD, substance use disorders [Colour figure can be viewed at wileyonlinelibrary.com] 


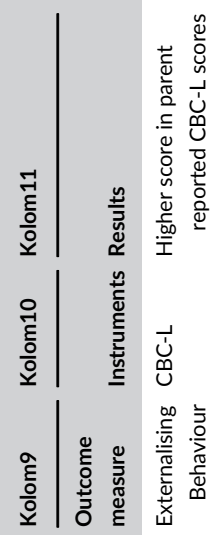

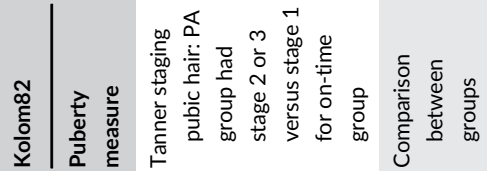

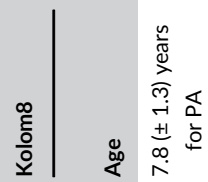

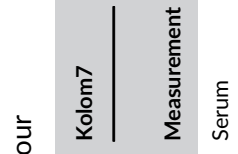

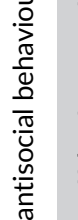

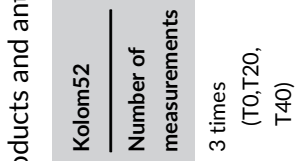

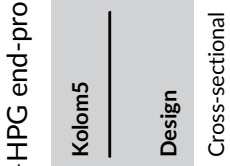

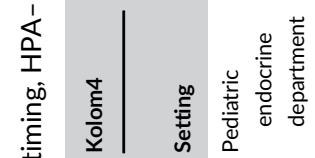

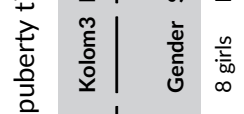

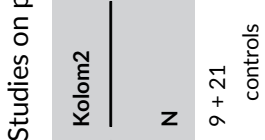

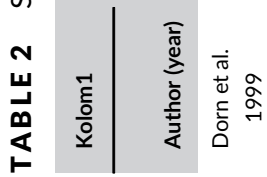

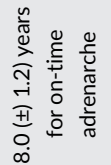

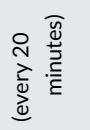

ঃे

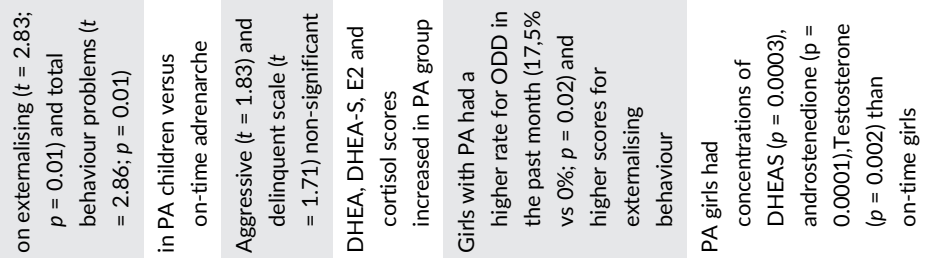

㟧

$\stackrel{\cup}{\underline{O}}$

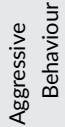

ชิ

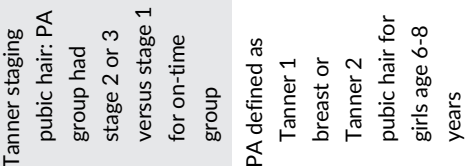

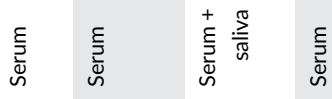

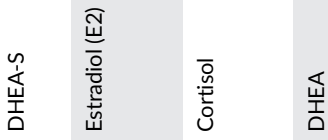

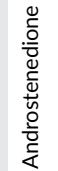

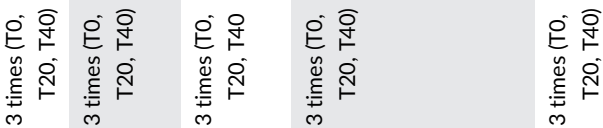

กั

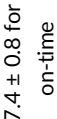

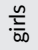

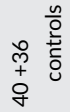

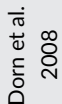



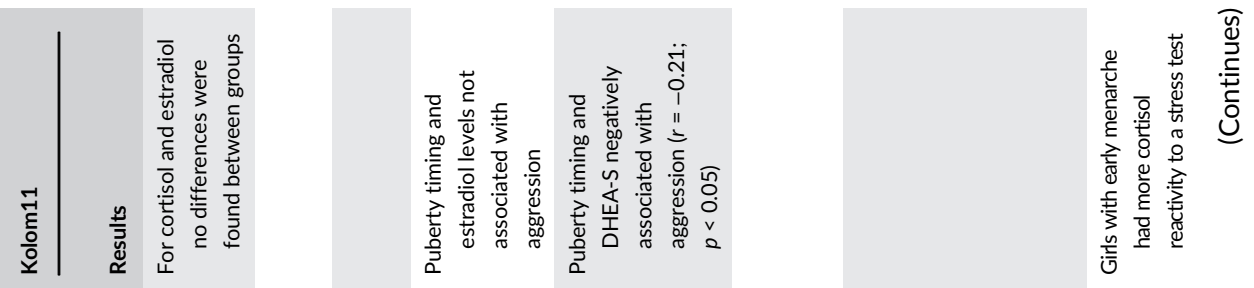

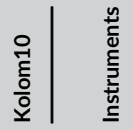

产

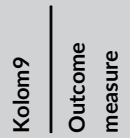

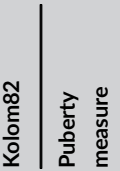

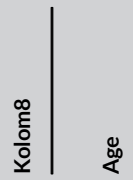

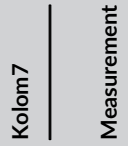

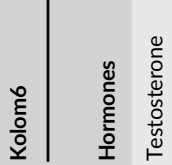

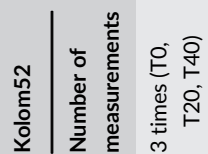

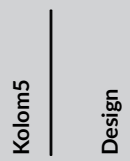

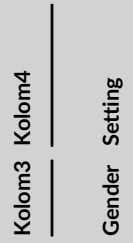

ปั

ธี

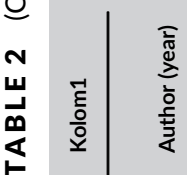

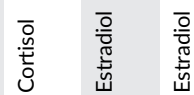

虰

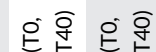

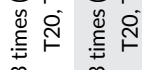

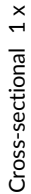

ธัญ

离芯

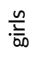

$\stackrel{8}{9}$

耪 商
产

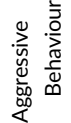

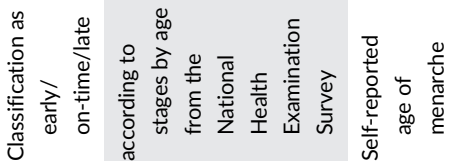

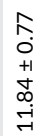

$\frac{\sqrt[\pi]{2}}{\sqrt{\pi}}$

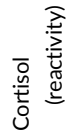

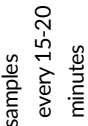

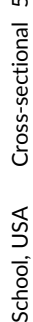

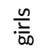

F

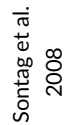



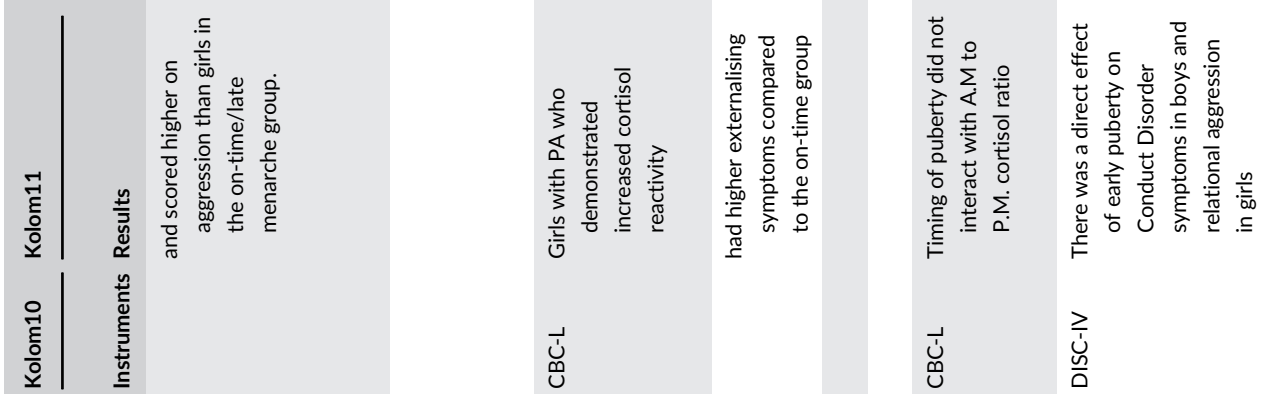

\section{نُ}

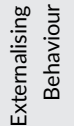
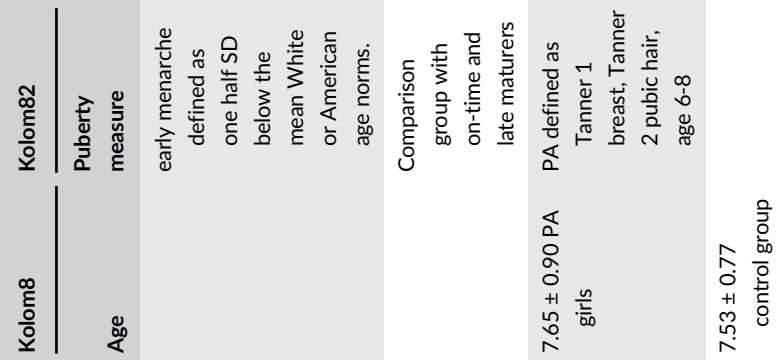

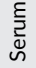

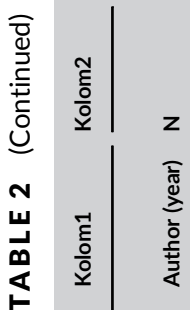

o
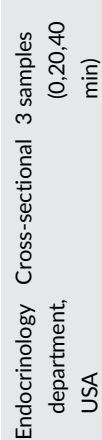

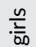

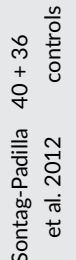

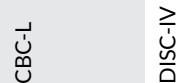

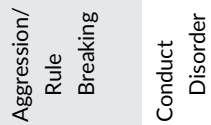

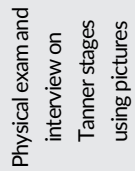

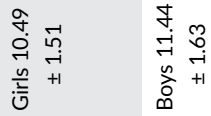

疍

$\overline{0}$
훙

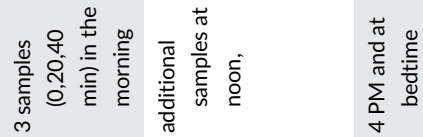

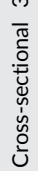

हैं

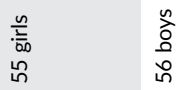

I

एक

矛客 

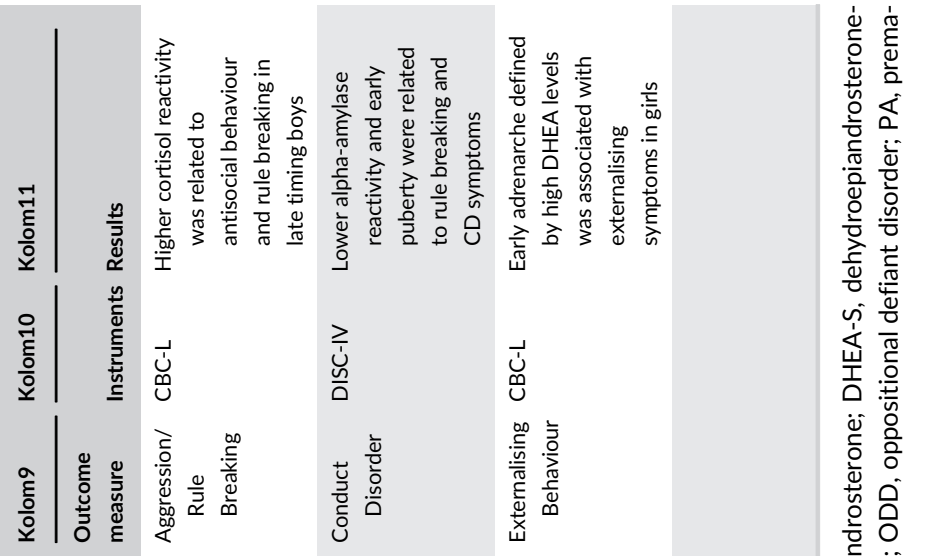

苍

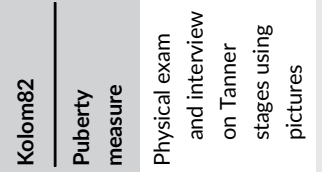

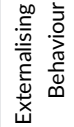

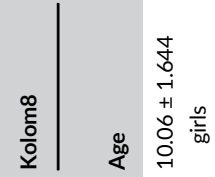

2
0
0
0
+1
0
0
0
0
0
0

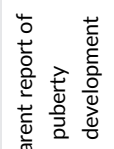

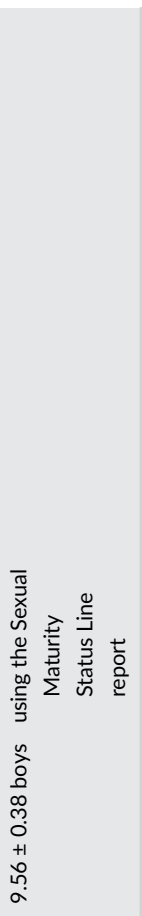

.

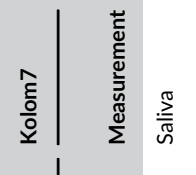

$\frac{\pi}{2}$

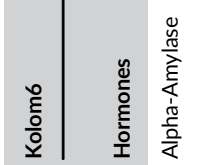

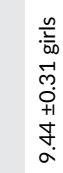

d)

वे

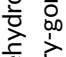

营

岌产

ปั $\frac{\sqrt{0}}{\frac{\pi}{4}}$

을 둥

ำ 옹

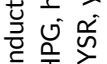

О I

$\frac{\sqrt[\pi]{2}}{\stackrel{\sqrt[\pi]{\pi}}{n}}$

ป

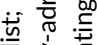

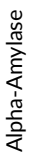

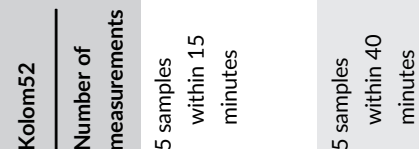

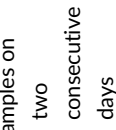

愛

焉

言 웡

完

章

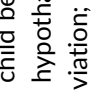

i

楒要

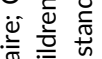

完 它

资

可 宩

产

금 उ 응

造

능

造

贻

ঃ

这完这

흐음

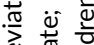

む

鼻高高 
Dorn et al. (2008). In contrast, Sontag-Padilla et al. (2012) found no evidence for an association between increased DHEA-S and androstenedione and externalising symptoms in PA girls and only a trend interaction between DHEA-S and lower levels of executive functioning with more externalising problems (Sontag-Padilla et al., 2012). Whittle et al. (2015) found higher DHEA levels to be associated with externalising symptoms in girls, but not boys, and found decreased affect-related brain activity in the mid-cingulate cortex and some other cortical and subcortical regions.

Girls with PA and higher serum cortisol levels measured after a stress test had more externalising behaviours than those with stable patterns (Sontag-Padilla et al., 2012). Dorn, Hitt, and Rotenstein (1999) found higher cortisol levels in a small sample of on-time girls, but in a later study (Dorn et al., 2008) they found no differences in cortisol between premature and on-time adrenarche girls.

Dorn et al. (2008) measured testosterone and oestradiol as well and found that testosterone levels were significantly higher for the PA girls who were more likely to have been given a diagnosis of ODD than the on-time group.

\subsection{Timing of gonadarche and menarche}

In one study, girls with early menarche who experienced higher levels of peer stress and exhibited stronger cortisol reactivity to a stress test were at greater risk of aggression, although this relationship was moderated by emotional/ cognitive numbing on the stress test (Sontag et al., 2008). Susman et al. (2010), by contrast, found no association between puberty and cortisol levels and behaviour among girls. In an earlier study, Susman et al. (2007), arguing that the morning: evening cortisol ratio is more reliable than a single morning cortisol sample, examined the hypothesis that early puberty timing and a low morning to evening cortisol ratio would be related to antisocial behaviour. Among 55 girls they found that puberty timing did not interact with the morning-to-evening cortisol ratio but did describe a general effect for timing of puberty on antisocial behaviour.

Graber et al. (2006) found a weak negative association between DHEA levels and aggression in 100 girls, but in this study no significant association was found between puberty timing and aggression, neither were oestradiol or DHEA tested as a mediator or moderator in this association. For oestradiol no association was found with aggression. The main conclusion of this study was that early puberty timing predicted higher emotional arousal and later depression, but not other behavioural disturbances.

\section{3 $\quad$ Adrenarche and gonadarche among boys}

With respect to adrenarche, Whittle et al. (2015) found no association between higher DHEA levels and externalising behaviour. Susman et al. (2010) found higher cortisol reactivity in later timing boys was related to a composite index of antisocial behaviour. In the study by Susman et al. (2007), like in girls, a general effect of early puberty timing was found on antisocial behaviour, irrespective of the morning-to-afternoon cortisol ratio.

No studies were found on boys and hormones of gonadarche, like testosterone or oestradiol.

\section{I DISCUSSION AND FUTURE DIRECTIONS}

In this review we sought to examine associations between adrenal and gonadal hormones and puberty timing as independent variables and antisocial behaviour as the dependent variable and found some support for an association between pre-six-year-old detection of adrenal androgens, such as DHEA, indicative of early adrenarche, and externalising symptoms in girls. The only study to include boys found no such association, but numbers were small (Whittle et al., 2015). 


\section{1 $\quad$ DHEA and premature adrenarche in girls}

A possible explanation for the findings among girls is that early adrenarche and DHEA rise may be a reflection of early life stress. Early life stress as a risk factor for later externalising disorders has been shown to have a long-lasting impact into adolescence on HPA-axis functioning (Essex et al., 2011; Roisman et al., 2009). Early adversity like absence of father or "negative parenting" before age 5 are thought to impact on puberty timing and tempo in girls (Ellis, 2004; Ellis, Shirtcliff, Boyce, Deardorff, \& Essex, 2011; Zhang, Zhang, \& Sun, 2019). From a developmental perspective the results found for girls may fit with the accentuation theory (Ge \& Natsuaki, 2009; Skoog \& Stattin, 2014), which implies transitional stress at puberty onset tends to accentuate previous emotional and behavioural difficulties.

\subsection{Cortisol reactivity in girls and boys}

As for cortisol reactivity girls with PA (Sontag-Padilla et al., 2012), girls with premature gonadarche (Sontag et al., 2008) and late timing boys (Susman et al., 2010) showed increased cortisol reactivity relating to higher risk of antisocial behaviours. When examining only the relationships between cortisol levels and externalising behaviours, Alink et al. (2008) found no overall relationships between them, so it seems likely that further study of this taking account of pubertal timing would be warranted.

The difference between boys and girls in this respect is in itself worthy of further exploration. While early puberty seems a candidate for a problematic mediator among girls it is late puberty in boys (Dorn et al., 2003; Graber, Seeley, Brooks-Gunn, \& Lewinsohn, 2004). Consideration of stress as a further mediator seems crucial, with early abuse being a common stress precursor among studied girls but the late gonadarche a stress in itself among the boys. Later maturing boys may be treated more according their stature than their biological age, possibly resulting in exclusion from same-age peer activities (Lindfors et al., 2007).

\subsection{Testosterone and premature adrenarche in girls}

Testosterone was positively associated with ODD (Dorn et al., 2008) in girls with PA versus on-time adrenarche. Similarly, they had higher DHEA-S and androstenedione concentrations, which are precursors for the production of testosterone. In girls testosterone has been linked to CD and DBD (Granger et al., 2003; Pajer et al., 2006), but in community samples no significant association was found (Dorn et al., 2009; Maras et al., 2003). These findings may fit with the diathesis stress model, which proposes that some children are vulnerable to exogenous stressors and endogenous stressors like the changes in endocrine milieu at puberty (Susman, Peckins, Bowes, \& Dorn, 2017; Zuckerman, 1999). While no study in this review calculated testosterone/cortisol ratios it is worth mentioning the testosterone/cortisol ratio has been positively associated with overt aggression in studies in adolescents in either clinical or detention settings (Dabbs et al., 1991; Popma et al., 2007; Tackett, Herzhoff, Harden, Page-Gould, \& Josephs, 2014). Hypothetically, cortisol and testosterone play a more significant role in early maturers: testosterone affects behaviour in an opposite way compared to cortisol. It stimulates behavioural activation, induces aggression and reduces fear and social withdrawal (Hermans, Putman, \& Van Honk, 2006). Cortisol increases fear, punishment sensitivity and behavioural inhibition (Schulkin, 2003; Van Honk \& Schutter, 2006). The balance between high testosterone levels and low cortisol levels shifts an individual to low punishment-high reward sensitivity (Carver \& Harmon-Jones, 2009) and risky decision making as measured with the lowa Gambling Task (Van Honk, Schutter, Hermans, \& Putman, 2003). It is important to note HPA and HPG axes are highly interactive and have antagonistic properties (Viau, 2002). For example, DHEA is derived from both the adrenal cortex and testes and is an important precursor for testosterone in males and oestradiol in females. 


\subsection{Strengths and limitations}

This is a first review of the inter-relationships between hormonal measures as indicative of the timing of puberty and how these relate to antisocial behaviours. Our search was systematic but limited to literature databases and follow up of references in included articles, however in a topic like this, it is unlikely that there will be grey literature unless possibly in the form of unpublished theses.

Main limitations, therefore, are in the small number of studies found and that the diversity of measures meant that meta-analysis was impossible. Further, all studies we included were cross-sectional, so neither directional nor causative conclusions can be drawn with any safety. It may be of interest that all studies found on hormonal markers were with community-based populations, so it may be that we were not able to tap into true disorder level antisocial behaviour disorders and this may partly account for the mixed findings. Finally, although stress was invoked as relevant, it was inconsistently measured.

\section{5 | CONCLUSIONS}

In conclusion we found some evidence for adrenal hormone, notably DHEA, indicative of PA in girls, being associated with antisocial behaviour. This adds to preliminary knowledge on the role of PA as a risk factor for antisocial behaviour. Contrary to expectation, deviant puberty timing was related to increased cortisol reactivity in both sexes, but early in girls and late among boys. The most important hormones relevant at puberty onset are adrenal in originboth androgens (DHEA) and cortisol. Although sample sizes were too small to allow firm conclusions, this indicates a potentially useful way forward in research, although in view of the feedback loops between hormonal axes, we recommend measures of all relevant hormones. Further directions for research would include prospective evaluation of long-term patterns of antisocial behaviours during and after puberty development and hormonal measures at standard time points and the mediating or moderating effect of stressors and their timing.

\section{CONFLICT OF INTEREST}

None.

\section{DATA AVAILABILITY STATEMENT}

Data sharing is not applicable to this article as no new data were created or analysed in this study.

\section{ORCID}

Philip Jules Simon Michielsen (D) https://orcid.org/0000-0003-1035-2459

\section{REFERENCES}

Alink, L. R. A., Van ljzendoorn, M. H., Bakermans-Kranenburg, M. J., Mesman, J., Juffer, F., \& Koot, H. M. (2008). Cortisol and externalizing behavior in children and adolescents: Mixed meta-analytic evidence for the inverse relation of basal cortisol and cortisol reactivity with externalizing behavior. Developmental Psychobiology, 50, 427-450. https://doi.org/ 10.1002/dev.20300

Balzer, B. W., Duke, S. A., Hawke, C. I., \& Steinbeck, K. S. (2015). The effects of estradiol on mood and behavior in human female adolescents: A systematic review. European Journal of Pediatrics, 174(3), 289-298. https://doi.org/10.1007/ s00431-014-2475-3

Belsky, J., Ruttle, P. L., Boyce, W. T., Armstrong, J. M., \& Essex, M. J. (2015). Early adversity, elevated stress physiology, accelerated sexual maturation and poor health in females. Developmental Psychology, 51, 816-822. https://doi.org/10. 1037/dev0000017

Beltz, A. M., Corley, R. P., Bricker, J. B., Wadsworth, S. J., \& Berenbaum, S. A. (2014). Modeling pubertal timing and tempo and examining links to behavior problems. Developmental Psychology, 50, 2715-2726. https://doi.org/10.1037/ a0038096 
Carver, C. S., \& Harmon-Jones, E. (2009). Anger is an approach related affect: Evidence and implications. Psychological Bulletin, 135, 183-204. https://doi.org/10.1037/a0013965

Celio, M., Karnik, N. S., \& Steiner, H. (2006). Early maturation as a risk factor for aggression and delinquency in adolescent girls: A review. International Journal of Clinical Practice, 60(10), 1254-1262. https://doi.org/10.1111/j.1742-1241.2006.00972.x

Cooke, A., Smith, D., \& Booth, A. (2012). Beyond PICO: The SPIDER tool for qualitative evidence synthesis. Qualitative Health Research, 22(10), 1435-1443. https://doi.org/10.1177/1049732312452938

Dabbs, J. M., Jurkovic, G. J., \& Frady, R. L. (1991). Salivary testosterone and cortisol among late adolescent male offenders. Journal of Abnormal Child Psychology, 19, 469-478.

Dorn, L. D., Dahl, R. D., Williamson, D. E., Birmaher, B., Axelson, D., \& Perel, J. (2003). Developmental markers in adolescence: Implications for studies in pubertal processes. Journal of Youth and Adolescence, 32, 315-324.

Dorn, L. D., Dahl, R. E., Woodward, H. R., \& Biro, F. M. (2006). Defining the boundaries of early adolescence: A user's guide to assessing pubertal status and pubertal timing in research with adolescents. Applied Developmental Science, 10(1), 30-56.

Dorn, L. D., Hitt, S. F., \& Rotenstein, D. (1999). Biopsychological and cognitive differences in children with premature vs. ontime adrenarche. Archives of Pediatrics \& Adolescent Medicine, 153(2), 137-146.

Dorn, L. D., Kolko, D. J., Susman, E. J., Huang, B., Stein, H., Music, E., \& Bukstein, O. G. (2009). Salivary gonadal and adrenal hormone differences in boys and girls with and without disruptive behavior disorders: Contextual variants. Biological Psychology, 81(1), 31-39.

Dorn, L. D., Rose, S. R., Rotenstein, D., Susman, E. J., Huang, B., Loucks, T. L., \& Berga, S. L. (2008). Differences in endocrine parameters and psychopathology in girls with premature adrenarche versus on-time adrenarche. Journal of Pediatric Endocrinology and Metabolism, 21(5), 439-448.

Ellis, B. J. (2004). Timing of pubertal maturation in girls: An integrated life history approach. Psychological Bulletin, 130, 920-958. https://doi.org/10.1037/0033-2909.130.6.920

Ellis, B. J., Shirtcliff, E. A., Boyce, W. T., Deardorff, J., \& Essex, M. J. (2011). Quality of early family relationships and the timing and tempo of puberty: effects depend on biological sensitivity to context. Development and Psychopathology, 23, 85-99. https://doi.org/10.1017/S0954579410000660

Essex, M. J., Shirtcliff, E. A., Burk, L. R., Ruttle, P. L., Klein, M. H., Slattery, M. J., \& Armstrong, J. M. (2011). Influence of early life stress on later hypothalamic-pituitary-adrenal axis functioning and its covariation with mental health symptoms: A study of the allostatic process from childhood into adolescence. Development and Psychopathology, 23, 1039-1058. https://doi.org/10.1017/S0954579411000484

Farrington, D. P. (1995). The twelfth Jack Tizard Memorial Lecture. The development of offending and antisocial behaviour from childhood: Key findings from the Cambridge Study in Delinquent Development. Journal of Child Psychology and Psychiatry, 36(6), 929-964.

Ge, X., \& Natsuaki, M. N. (2009). In search of explanations for early pubertal timing effects on developmental psychopathology. Current Directions in Psychological Science, 18(6), 327-331.

Graber, J. A. (2013). Pubertal timing and the development of psychopathology in adolescence and beyond. Hormones and Behavior, 64, 262-269. https://doi.org/10.1016/j.yhbeh.2013.04.003

Graber, J. A., Brooks-Gunn, J., \& Warren, M. P. (2006). Pubertal effects on adjustment in girls: Moving from demonstrating effects to identifying pathways. Journal of Youth and Adolescence, 35, 413-423.

Graber, J. A., Seeley, J. R., Brooks-Gunn, J., \& Lewinsohn, P. M. (2004). Is pubertal timing associated with psychopathology in young adulthood? Journal of the American Academy of Child and Adolescent Psychiatry, 43(6), 718-726. https://doi. org/10.1097/01.chi.0000120022.14101.11

Granger, D. A., Shirtcliff, E. A., Zahn-Waxler, C., Usher, B., Klimes-Dougan, B., \& Hasting, P. (2003). Salivary testosterone diurnal variation and psychopathology in adolescent males and females: Individual differences and developmental effects. Development and Psychopathology, 15, 431-449.

Grumbach, M. M., \& Styne, D. M. (2003). Puberty: Ontogeny, neuroendocrinology, physiology, and disorders. In P. R. Larsen, H. M. Kronenberg, S. Melmed, \& K. S. Polonsky (Eds.), Williams Textbook of Endocrinology (pp. 1115-1286). New York, NY: Oxford University Press.

Hemphill, S. A., Kotevski, A., Herrenkohl, T. I., Toumbourou, J. W., Carlin, J. B., Catalano, R. F., \& Patton, G. C. (2010). Pubertal stage and the presence of violence and social relational aggression. Pediatrics, 126(2), e298-e305. https://doi.org/ 10.1542/peds.2009-0574

Hermans, E. J., Putman, P., \& Van Honk, J. (2006). Testosterone acutely reduces the fear potentiated startle. Biological Psychiatry, 59, 872-874.

Ibanez, L., Dimartino-Nardi, J., Potau, N., \& Saenger, P. (2000). Premature adrenarche-Normal variant or forerunner of adult disease? Endocrine Reviews, 21, 671-696. https://doi.org/10.1210/edrv.21.6.0416

Kretschmer, T., Oliver, B. R., \& Maughan, B. (2014). Pubertal development, spare time activities, and adolescent delinquency: testing the contextual amplification hypothesis. Journal of Youth and Adolescence, 43, 1346-1360. https://doi.org/10. 1007/s10964-013-0074-7 
Lindfors, K., Elovainio, M., Wickman, S., Vuorinen, R., Sinkkonen, J., Dunkel, L., \& Raappana, A. (2007). The role of ego development in psychosocial adjustment among boys with delayed puberty. Journal of Research on Adolescence, 17, $601-612$.

Maras, A., Laucht, M., Gerdes, D., Wilhem, C., Lewicka S., Haack, D., \& Schmidt, M. H. (2003). Association of testosterone and dihydrotestosterone with externalizing behavior in adolescent boys and girls. Psychoneuroendocrinology, 28, 932-940.

Marceau, K., Ram, N., Houts, R. M., Grimm, K. J., \& Susman, E. J. (2011). Individual differences in boys' and girls' timing and tempo of puberty: Modeling development with nonlinear growth models. Developmental Psychology, 47, 1389-1409. https://doi.org/10.1037/a0023838

Maughan, B., \& Rutter, M. (2001). Antisocial children grown up. In J. Hill \& B. Maughan (Eds.), Conduct disorders in childhood and adolescence (pp. 507-552). Cambridge, England: Cambridge University Press.

Mendle, J., Turkheimer, E., \& Emery, R. E. (2007). Detrimental psychological outcomes associated with early pubertal timing in adolescent girls. Developmental Review, 27(2), 151-171. https://doi.org/10.1016/j.dr.2006.11.001

Moffitt, T. E. (2006). Life-course persistent versus adolescence-limited antisocial behavior. In D. Cicchetti \& J. Cohen (Eds.), Developmental psychopathology: Risk, disorder, and adaptation (2nd ed., pp. 570-598). New York, NY: Wiley.

Mundy, L. K., Romaniuk, H., Canterford, L., Hearps, S., Viner, R. M., Bayer, J. K., ... Patton, G. C. (2015). Adrenarche and the emotional and behavioral problems of late childhood. Journal of Adolescent Health, 57(6), 608-616. https://doi.org/10. 1016/j.jadohealth.2015.09.001

Negriff, S., \& Susman, E. J. (2011). Pubertal timing, depression, and externalizing problems: A framework, review, and examination of gender differences. Journal of Research on Adolescence, 21(3), 717-746.

Nottelmann, E. D., Susman, E. J., Blue, J. H., Inoff-Germain, G., Dorn, L. D., \& Loriaux, D. L. (1987). Gonadal and adrenal hormone correlates of adjustment in early adolescence. In R. M. Lerner \& T. T. Foch (Eds.), Biological-psychological interactions in early adolescence. Hilssdale, NJ: Erlbaum.

Odgers, C. L., Moffitt, T. E., Broadbent, J. M., Dickson, N., Hancox, R. J., Harrington, H., \& Caspi, A. (2008). Female and male antisocial trajectories: From childhood origins to adult outcomes. Development and Psychopathology, 20, $673-716$. https://doi.org/10.1017/S0954579408000333

Oldehinkel, A. J., Verhulst, F. C., \& Ormel, J. (2011). Mental health problems during puberty: Tanner stage-related differences in specific symptoms. The TRAILS study. Journal of Adolescence, 34, 73-85. https://doi.org/10.1016/j. adolescence.2010.01.010

Pajer, K., Tabbah, R., Gardner, W., Rubin, R. T., Czambel, R. K., \& Wang, Y. (2006). Adrenal androgen and gonadal hormone levels in adolescent girls with conduct disorder. Psychoneuroendocrinology, 31(10), 1245-1256.

Petersen, A. C., Crockett, L. J., Richards, M., \& Boxer, A. (1988). A self-report measure of pubertal status: Reliability, validity, and initial norms. Journal of Youth and Adolescence, 17, 117-133. https://doi.org/10.1007/BF01537962

Popma, A., Vermeiren, R., Geluk, C. A., Rinne, T., Van den Brink, W., Knol, D. L., ... Doreleijers, T. A. (2007). Cortisol moderates the relationship between testosterone and aggression in delinquent male adolescents. Biological Psychiatry, 61, 405-411. https://doi.org/10.1016/j.biopsych.2006.06.006

Roisman, G., Susman, E. J., Booth-LaForce, C., Belsky, J., Houts, R., Barnett-Walker, K., \& Steinberg, L. (2009). Early family and child-care antecedents of awakening cortisol levels in adolescence. Child Development, 80, 907-920. https://doi. org/10.1111/j.1467-8624.2009.01305.x

Scerbo, A. S., \& Kolko, D. J. (1994). Salivary testosterone and cortisol in disruptive children: Relationship to aggressive, hyperactive and internalizing behaviors. Journal of the American Academy of Child and Adolescent Psychiatry, 33, 1174-1184.

Schulkin, J. (2003). Rethinking homeostasis. Allostatic regulation in physiology and pathophysiology. Cambridge, MA: MIT Press.

Shirtcliff, E. A., Zahn-Waxler, C., Klimes-Dougan, B., \& Slattery, M. (2007). Salivary dehydroepiandrosterone responsiveness to social challenge in adolescents with internalizing problems. Journal of Child Psychology and Psychiatry, 48, 580-591. https://doi.org/10.1111/j.1469-7610.2006.01723.x

Sisk, C. L., \& Foster, D. L. (2004). The neural basis of puberty and adolescence. Nature Neuroscience, 7(10), 1040-1047. https://doi.org/10.1038/nn1326

Skoog, T., \& Stattin, H. (2014). Why and under what contextual conditions do early-maturing girls develop problem behaviors? Child Development Perspectives, 8, 158-162. https://doi.org/10.1111/cdep.12076

Sontag, L. M., Graber, J. A., Brooks-Gunn, J., \& Warren, M. P. (2008). Coping with social stress: Implications for psychopathology in young adolescent girls. Journal of Abnormal Child Psychology, 36, 1159-1174. https://doi.org/10.1007/ s10802-008-9239-3

Sontag-Padilla, L. M., Dorn, L. D., Tissot, A., Susman, E. J., Beers, S. R., \& Rose, S. R. (2012). Executive functioning, cortisol reactivity, and symptoms of psychopathology in girls with premature adrenarche. Development and Psychopathology, 24, 211-223. https://doi.org/10.1017/S0954579411000782

Susman, E. J., Dockray, S., Granger, D. A., Blades, K. T., Randazzo, W., Heaton, J. A., \& Dorn, L. D. (2010). Cortisol and alpha amylase reactivity and timing of puberty: Vunerabilities for antisocial behaviour in young adolescents. Psychoneuroendocrinology, 35, 557-569. https://doi.org/10.1016/j.psyneuen.2009.09.004 
Susman, E. J., Dockray, S., Schiefelbein, V. L., Herwehe, S., Heaton, J. A., \& Dorn, L. D. (2007). Morningness/eveningness, morning-to-afternoon cortisol ratio, and antisocial behavior problems during puberty. Developmental Psychology, 43, 811-822. https://doi.org/10.1037/0012-1649.43.4.811

Susman, E. J., Granger, D. A., Murowchick, E., Ponirakis, A., \& Worral, B. K. (1996). Gonadal and adrenal hormones. Developmental transitions and aggressive behavior. Annals of the New York Academy of Sciences, 794, 18-30.

Susman, E. J., Inoff-Germain, G., Nottelmann, E. D., Loriaux, D. L., Cutler, G. B., \& Chrousos, G. P. (1987). Hormones, emotional dispositions and aggressive attributes in young adolescents. Child Development, 58, 1114-1134.

Susman, E. J., Peckins, M. K., Bowes, J. L., \& Dorn, L. D. (2017). Longitudinal synergies between cortisol reactivity and diurnal testosterone and antisocial behavior in young adolescents. Development and Psychopathology, 29(4), $1353-1369$. https://doi.org/10.1017/S0954579416001334

Tackett, J. L., Herzhoff, K., Harden, K. P., Page-Gould, E., \& Josephs, R. A. (2014). Personality $\times$ hormone interactions in adolescent externalizing psychopathology. Personality Disorders, 5(3), 235-246. https://doi.org/10.1037/per0000075

Tremblay, R.E., Schaal, B., Boulerice, B., Arsenault, L., Soussignan, R., \& Perusse, D. (1997). Male physical aggression, social dominance, and testosterone levels at puberty. A developmental perspective. In: Raine A., Brennan P.A., Farrington D.P., Mednick S.A. Biosocial bases of violence, Plenum Press, New York, NY, 271-291.

Ullsperger, J. M., \& Nikolas, M. A. (2017). A meta-analytic review of the association between pubertal timing and psychopathology in adolescence: Are there sex differences in risk? Psychological Bulletin, 143, 903-938. https://doi.org/10.1037/ bul0000106

Van Bokhoven, I., Van Goozen, S. H., Van Engeland, H., Schaal, B., Arseneault, L., Seguin, J. R., ... Tremblay, R. E. (2006). Salivary testosterone and aggression, delinquency, and social dominance in a population-based longitudinal study of adolescent males. Hormones and Behavior, 50, 118-125.

Van Goozen, S. H., Matthys, W., Cohen-Kettenis, P. T., \& Buitelaar, J. K. (2000). Hypothalamic-pituitary-adrenal axis and autonomic nervous system activity in disruptive children and matched controls. Journal of the American Academy of Child and Adolescent Psychiatry, 39, 1438-1445.

Van Goozen, S. H. M., Matthys, W., Cohen-Kettenis, P. T., Thijssen, J. H. H., \& Van Engeland, H. (1998). Adrenal androgens and aggression in conduct disorder prepubertal boys and normal controls. Biological Psychiatry, 43, 156-158.

Van Honk, J., \& Schutter, D. J. (2006). Unmasking feigned sanity: A neurobiological model of emotion processing in primary psychopathy. Cognitive Neuropsychiatry, 11, 285-306. https://doi.org/10.1080/13546800500233728

Van Honk, J., Schutter, D. J., Hermans, E. J., \& Putman, P. (2003). Low cortisol levels and the balance between punishment sensitivity and reward dependency. NeuroReport, 14, 1993-1996. https://doi.org/10.1097/01.wnr.0000091690. 72892.ec

Viau, V. (2002). Functional cross-talk between the hypothalamic-pituitary-gonadal and adrenal axes. Journal of Neuroendocrinology, 14(6), 506-513.

Voutilainen, R., \& Jääskeläinen, J. (2015). Premature adrenarche: Etiology, clinical findings, and consequences. Journal of Steroid Biochemistry and Molecular Biology, 145, 226-236. https://doi.org/10.1016/j.jsbmb.2014.06.004

Whittle, S., Simmons, J. G., Byrne, M. L., Strikwerda-Brown, C., Kerestes, R., Seal, M. L., ... Allen, N. B. (2015). Associations between early adrenarche, affective brain function and mental health in children. Social Cognitive and Affective Neuroscience, 10, 1282-1290. https://doi.org/10.1093/scan/nsv014

Zhang, L., Zhang, D., \& Sun, Y. (2019). Adverse childhood experiences and early pubertal timing among girls: A meta-analysis. International Journal of Environmental Research and Public Health, 16(16), 2887. https://doi.org/10.3390/ijerph16162887

Zuckerman, M. (1999). Vulnerability to psychopathology: A biosocial model. Washington, DC: American Psychological Association.

\section{SUPPORTING INFORMATION}

Additional supporting information may be found online in the Supporting Information section at the end of this article.

How to cite this article: Michielsen PJS, Roza SJ, HJC van Marle. Endocrine markers of puberty timing and antisocial behaviour in girls and boys. Crim Behav Ment Health. 2020;1-15. https://doi.org/10.1002/

cbm.2149 